\title{
Study of Geosmin and 2-Methylisoborneol (MIB) Producers in Phayao Lake, Thailand
}

\author{
Niwooti Whangchai ${ }^{1 *}$, Tipsukon Pimpimon ${ }^{1}$, Udomlak Sompong ${ }^{1}$, Supannee Suwanpakdee ${ }^{2}$, \\ Redel Gutierrez ${ }^{3}$, Tomoaki Itayama ${ }^{4}$ \\ ${ }^{1}$ Faculty of Fisheries Technology and Aquatic Resources, Maejo University, Sansai, Chiang Mai, 50210, \\ Thailand. \\ 2 Department of Fisheries, Faculty of Natural Resources, Rajamangala University of Technology Isan, Sakon \\ Nakhon Campus, Sakon Nakhon , 47160 Thailand. \\ 3 College of Arts and Sciences, Central Luzon State University, Science City of Munoz, Nueva Ecija, 3120, \\ Philippines. \\ ${ }^{4}$ Graduate School of Engineering, Nagasaki University, 1-14, Bunkyoumachi, Nagasaki, 852-8521, Japan. \\ * Corresponding author. Tel.: 66 869166825; email: niwooti@hotmail.co.th \\ Manuscript submitted November 20, 2016; accepted March 7, 2017. \\ doi: 10.17706/ijbbb.2017.7.2.177-184
}

\begin{abstract}
This study aimed to investigate geosmin and 2-methylisoborneol (MIB)-producing cyanobacteria and actinomycetes as sources of earthy-musty odours in Phayao Lake, northern Thailand. Known earthy-musty odour producers, Lyngbya sp., Phormidium sp., Anabaena sp. and Oscillatoria sp., were found as the dominant genera of cyanobacteria in the lake water. Odour-producing Streptomyces spp. were also found to be significantly present in the lake sediment where majority of Streptomyces spp. (63\%) isolated were geosmin-producers. The significant density of actinomycetes, particularly Streptomyces, suggests that they played as important contributor to the production of geosmin and MIB in the lake.
\end{abstract}

Key words: Geosmin, MIB, phayao lake, musty odour producers.

\section{Introduction}

Currently, many areas of Thailand are facing water shortages, especially during the dry season. Moreover, water quality of lakes and surface waters in the country is deteriorating due to anthropogenic activities such as farming and urbanization, causing widespread eutrophication. One of these lakes is Phayao Lake (Kwan Phayao, in Thai), a semi-freshwater lake which plays an important role in the socio-economic development of Phayao province. Considered as one of the largest artificial lakes in northern Thailand [1], Phayao Lake is a popular tourist destination, a raw water source for water supply and a fishing ground for the local fishery. Livestock effluent from the basin and sewage discharges from the city is likely the major pollution sources. These significant sources of nutrients, especially nitrogen and phosphorus, contribute to the eutrophication of the lake [2]. Eutrophication leads to algal blooms and subsequently to taste and odor compounds, geosmin and 2-methylisoborneol (MIB) production, reducing the application of the lake water for drinking and contaminating aquatic animals. Moreover, hepatotoxin microcystin formation in Phayao Lake was also implicated with algal blooms [2].

Common taste and odor compounds, geosmin and MIB, are secondary terpenoid metabolites produced by 
certain species of cyanobacteria and actinomycetes (filamentous actinobacteria) [3] that imparts earthy and musty odor to water at extremely low concentrations $(<5 \mathrm{ng} / \mathrm{L})$. Since cyanobacteria are considered to be the chief source of these compounds in aquatic systems, common microorganisms in most aquatic environments such as actinomycetes, became an important biological source of taste and odor compounds. In Japan, Sugiura and Nakano [4] isolated 40 strains of actinomycetes from the sediments of Lake Kasumigaura. All these species were found to produce both geosmin and MIB. It is highly likely that due to the increased annual nutrient loadings to the lake, the result will be an environment more suitable for actinomycete growth since algal cells are a carbon source for actinomycetes and do enhance growth.

The significance of earthy-musty odour production by actinomycetes in Phayao Lake has not been studied, as well as the occurrence of these bacteria. The purpose of this research was to investigate the abundance of actinomycetes, other than cyanobacteria, in water and sediment of Phayao Lake.

\section{Materials and Methods}

\subsection{Water and Sediment Sampling}

Water and sediment samples were collected from 6 stations (S1-S6) in Phayao Lake for a period of 8 months, from June 2012-February 2013 (Fig. 1).

Samples for physico-chemical (1.5L) and earthy-musty odour analyses $(120 \mathrm{~mL})$ were collected directly from the water surface at 20-40 cm depth. Lake water (5 L) for phytoplankton evaluation was filtered with a plankton net of $25 \mu \mathrm{m}$ mesh, concentrated in 30-mL bottles and added with 3 drops of Lugol's solution as preservative. Identification and counts of phytoplankton genera/species were determined using a light microscope (Olympus BH2, Japan), and picture database and related texts such as Peerapornpisal [5]. Sediment material (about $500 \mathrm{~g}$ from the upper $0.5 \mathrm{~cm}$ sediment) was collected using a plastic dipper attached to a PVC pole and placed in wide-mouthed 200-mL plastic bottles. All water and sediment samples were kept on ice until transported to the laboratory.

\subsection{Geosmin and MIB Analysis}

Geosmin and MIB (dissolved and particulate fractions) were extracted from water and sediment samples using solid phase microextraction (SPME). Gas chromatography-mass spectrometry (GC/MS) was used for quantification at a limit of detection of $0.01 \mu \mathrm{gL}^{-1}$ for both geosmin and MIB according to Gutierrez et al. [6].

\subsection{Isolation and Screening of Streptomycetes in Sediments}

Sediment samples $(10 \mathrm{~g})$ were mixed with $90 \mathrm{~mL}$ of $0.85 \% \mathrm{NaCl}$ solution, shaken at $150 \mathrm{rpm}$ for 30 minutes at room temperature and serially diluted ten folds to $10^{-5}$. Soil suspensions $(100 \mu \mathrm{L})$ from $10^{-3}, 10^{-4}$ and $10^{-5}$ dilution were spread onto the surface of starch casein agar (SCA) plates, and incubated at $30^{\circ} \mathrm{C}$ for 7-14 days. Actinomycetes were assigned into streptomycetes (filamentous and fungus-like sporulation structures) and non-streptomycetes groups. Colonies from both groups were counted and recorded as CFU $\mathrm{g}^{-1}$. Earthy-musty odour-producing streptomycetes were purified by re-streaking on SCA, sealed with paraffin film and incubated at $30^{\circ} \mathrm{C}$ for $7-14$ days or until complete sporulation was observed. The isolates were screened whether they are geosmin or MIB producer by GC/MS [7].

\subsection{Data Analysis}

Analysis of variance (ANOVA) was used to test for difference between means of observed parameters and each treatment. Duncan Multiple Range Test (DMRT) at 95\% confidence level was used for treatment comparison. Relationships between water quality variables and earthy-musty odour compounds were analysed using Pearson correlation analysis. Significant correlation was assumed when $\mathrm{p}<0.05$ in either positive or negative correlations. 


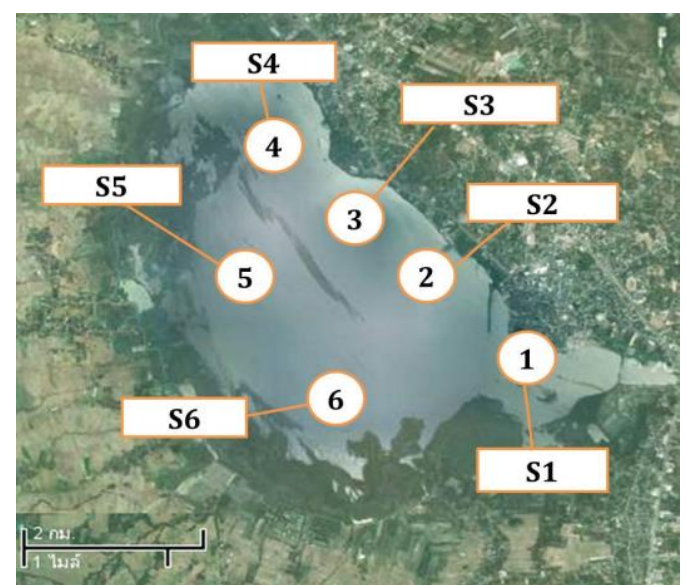

Fig. 1. Collection points at Phayao Lake: S1-3 city areas, S-6 agricultural areas [7].

\section{Results and Discussion}

\subsection{Water Quality and Chlorophyll a Levels}

Table 1. Physico-Chemical and Biological Characteristics of Phayao Lake

\begin{tabular}{|c|c|c|c|c|c|c|}
\hline \multirow{2}{*}{ Parameters } & \multicolumn{6}{|c|}{ Collection points in Phayao Lake } \\
\hline & S1 & S2 & S3 & S4 & S5 & S6 \\
\hline Temperature $\left({ }^{\circ} \mathrm{C}\right)$ & $28.1 \pm 2.37$ & $28.2 \pm 1.86$ & $28.8 \pm 2.62$ & $28.6 \pm 2.54$ & $28.7 \pm 2.29$ & $28.4 \pm 2.04$ \\
\hline DO $\left(\mathrm{mg} \mathrm{L}^{-1}\right)$ & $5.61 \pm 2.05$ & $6.15 \pm 1.92$ & $7.88 \pm 1.45$ & $6.38 \pm 2.80$ & $5.68 \pm 1.59$ & $5.46 \pm 2.21$ \\
\hline Conductivity $\left(\mathrm{mS} \mathrm{cm}^{-1}\right)$ & $11.4 \pm 1.75$ & $12.0 \pm 1.93$ & $11.1 \pm 2.01$ & $10.6 \pm 2.14$ & $12.9 \pm 1.54$ & $12.7 \pm 1.17$ \\
\hline Turbidity (NTU) & $45.0 \pm 21.0$ & $49.1 \pm 19.5$ & $50.0 \pm 19.6$ & $30.5 \pm 25.5$ & $34.3 \pm 18.0$ & $34.3 \pm 12.1$ \\
\hline \multirow[t]{2}{*}{ TAN (mg L-1) } & $0.075 \pm 0.070$ & $0.086 \pm 0.093$ & $0.023 \pm 0.033$ & $0.039 \pm 0.040$ & $0.046 \pm 0.036$ & $0.041 \pm 0.04$ \\
\hline & & & & & & 1 \\
\hline \multirow[t]{2}{*}{$\mathrm{NO}^{-}{ }_{2}-\mathrm{N}\left(\mathrm{mg} \mathrm{L}^{-1}\right)$} & $0.001 \pm 0.002$ & $0.001 \pm 0.001$ & $0.001 \pm 0.002$ & $0.002 \pm 0.002$ & $0.001 \pm 0.002$ & $0.001 \pm 0.00$ \\
\hline & & & & & & 2 \\
\hline \multirow[t]{2}{*}{$\mathrm{NO}_{3}^{-}-\mathrm{N}\left(\mathrm{mg} \mathrm{L}^{-1}\right)$} & $0.013 \pm 0.018$ & $0.012 \pm 0.013$ & $0.010 \pm 0.018$ & $0.010 \pm 0.005$ & $0.010 \pm 0.012$ & $0.016 \pm 0.01$ \\
\hline & & & & & & 8 \\
\hline \multirow[t]{2}{*}{$\mathrm{PO}_{4}^{3-\mathrm{P}}\left(\mathrm{mg} \mathrm{L}^{-1}\right)$} & $0.015 \pm 0.016$ & $0.017 \pm 0.012$ & $0.028 \pm 0.025$ & $0.020 \pm 0.015$ & $0.021 \pm 0.018$ & $0.023 \pm 0.01$ \\
\hline & & & & & & 4 \\
\hline TSS (mg L-1) & $15.7 \pm 6.79$ & $14.8 \pm 8.42$ & $15.1 \pm 10.54$ & $10.8 \pm 8.06$ & $10.0 \pm 7.60$ & $8.21 \pm 6.75$ \\
\hline Chlorophyll a ( $\left.\mu \mathrm{g} \mathrm{L}^{-1}\right)$ & $33.98 \pm 22.27 \mathrm{ab}$ & $43.89 \pm 34.50^{\mathrm{b}}$ & $32.30 \pm 22.0^{\mathrm{ab}}$ & $14.40 \pm 10.83^{a}$ & $11.49 \pm 2.06^{\mathrm{a}}$ & $11.63 \pm 6.95^{\mathrm{a}}$ \\
\hline
\end{tabular}

The water quality parameters monitored (such as $\mathrm{pH}$, temperature, DO, conductivity, turbidity, total ammonia-nitrogen, nitrite-nitrogen, nitrate-nitrogen, orthophosphate-phosphorus and TSS) were not significantly different among the 6 stations (Table 1). Mean chlorophyll-a concentration in the 3 stations (S1-3) adjacent to the city were significantly $(p<0.05)$ higher compared to those in other collection points (S4-6).

A total of 40 different genera from 6 divisions of phytoplankton were identified in Phayao Lake namely, Cyanophyta, Chlorophyta, Chromophyta, Bacillariophyta, Euglenophyta and Cryptophyta. Composition-wise, Chlorophyta was the most abundant but Cyanophyta (cyanobacteria) dominated the lake water (Table 2). Oscillatoria, followed by Microcystis and Anabaena comprised the dominant cyanobacteria which are known 
producers of earthy-musty odour including Phormidium and Lyngbya (Fig. 2). Microcystis was included in the odour-producing list because there were claims that some species have the potential to produce geosmin apart from hepatotoxins (microcystins) [8]-[10]. These cyanobacteria except Phormidium were also found in a previous study [11] conducted in Phayao Lake. However, there was no record of which cyanobacterial species or genus dominated the lake during the time of their study. Prommana [12] on the other hand reported that Microcystis aeruginosa Kutz and Microcystis wesenbergii Kom. dominated Phayao Lake during a survey conducted from 1999 to 2000. However, the study mainly focused on the survey of microcystin-producing species present in the lake rather than cyanobacterial diversity in general.

\subsection{Phytoplankton Composition and Diversity}

Table 2. Biovolume of Phytoplankton (Mean \pm SE) in Phayao Lake

\begin{tabular}{|c|c|c|c|c|c|c|}
\hline \multirow{2}{*}{$\begin{array}{l}\text { Division/Gen } \\
\text { era/Species }\end{array}$} & \multicolumn{6}{|c|}{ Biovolume of phytoplankton in each station $\left(\mu \mathrm{L} \mathrm{L}^{-1}\right)$} \\
\hline & S1 & S2 & S3 & S4 & $\begin{array}{l}\text { S5 } \\
\end{array}$ & S6 \\
\hline Cyanophyta & $4.6066 \pm 1.655$ & $9.6432 \pm 6.523$ & $111.479 \pm 5.833$ & $2.2018 \pm 1.211$ & $0.8278 \pm 0.310$ & $0.9963 \pm 0.366$ \\
\hline Chlorophyta & $0.5380 \pm 0.193$ & $3.0109 \pm 2.499$ & $0.7267 \pm 0.306$ & $0.3930 \pm 0.187$ & $0.1910 \pm 0.095$ & $0.1966 \pm 0.096$ \\
\hline Chrysophyta & $0.0187 \pm 0.015$ & $0.0150 \pm 0.015$ & $0.0280 \pm 0.028$ & $0.0251 \pm 0.022$ & $0.0084 \pm 0.006$ & $0.0191 \pm 0.012$ \\
\hline $\begin{array}{l}\text { Bacillariophy } \\
\text { ta }\end{array}$ & $0.1173 \pm 0.051$ & $0.2096 \pm 0.121$ & $0.0996 \pm 0.053$ & $0.0222 \pm 0.016$ & $0.0565 \pm 0.034$ & $0.0563 \pm 0.026$ \\
\hline $\begin{array}{l}\text { Euglenophyt } \\
\text { a }\end{array}$ & $0.0002 \pm 0.000$ & $0.0002 \pm 0.000$ & $0.0054 \pm 0.005$ & $0.0014 \pm 0.001$ & $0.0002 \pm 0.000$ & $0.0016 \pm 0.001$ \\
\hline Cryptophyta & $0.0173 \pm 0.009$ & $0.0145 \pm 0.012$ & $0.0292 \pm 0.015$ & $0.0238 \pm 0.014$ & $0.0058 \pm 0.005$ & $0.0114 \pm 0.010$ \\
\hline $\begin{array}{c}\text { Div. } \\
\text { Cyanophyta }\end{array}$ & & & & & & \\
\hline Anabaena sp. & $1.2101 \pm 0.628$ & $0.5277 \pm 0.195$ & $1.1677 \pm 0.544$ & $0.2195 \pm 0.100$ & $0.1577 \pm 0.089$ & $0.1184 \pm 0.060$ \\
\hline $\begin{array}{l}\text { Chroococcus } \\
\text { sp. }\end{array}$ & - & - & $0.0320 \pm 0.032$ & 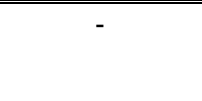 & 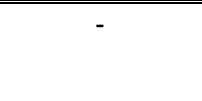 & - \\
\hline Lyngbya sp. & 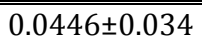 & - & - & - & 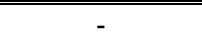 & 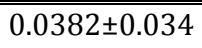 \\
\hline $\begin{array}{l}\text { Microcystis } \\
\text { aeruginosa } \\
\text { Kützing }\end{array}$ & $0.5140 \pm 0.153$ & $0.6844 \pm 0.278$ & $0.6902 \pm 0.258$ & $0.3660 \pm 0.210$ & $0.0806 \pm 0.043$ & $0.1002 \pm 0.053$ \\
\hline $\begin{array}{l}\text { M. } \\
\text { wesenbergii } \\
\text { Komárek }\end{array}$ & $0.6755 \pm 0.321$ & $1.1323 \pm 0.726$ & $1.6499 \pm 0.827$ & $0.7670 \pm 0.591$ & $0.0863 \pm 0.038$ & $0.0623 \pm 0.028$ \\
\hline $\begin{array}{l}\text { Oscillatoria } \\
\text { sp. }\end{array}$ & 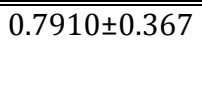 & 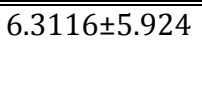 & 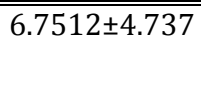 & 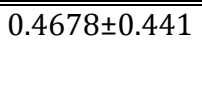 & 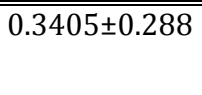 & 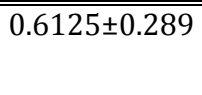 \\
\hline O. princeps & $0.9248 \pm 0.924$ & - & - & - & 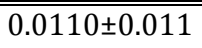 & - \\
\hline $\begin{array}{l}\text { O. } \\
\text { cf.pseudogem } \\
\text { inata }\end{array}$ & $0.0676 \pm 0.067$ & 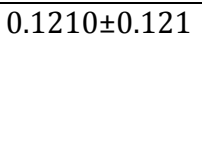 & $0.0481 \pm 0.048$ & - & 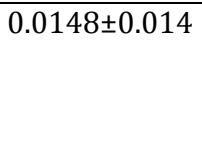 & - \\
\hline $\begin{array}{l}\text { Raphidiopsis } \\
\text { sp. }\end{array}$ & $0.0005 \pm 0.000$ & - & $0.0010 \pm 0.001$ & - & $0.0683 \pm 0.068$ & $0.0001 \pm 0.000$ \\
\hline R. curvata & $0.0075 \pm 0.007$ & 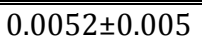 & 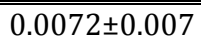 & - & - & - \\
\hline
\end{tabular}




\begin{tabular}{|c|c|c|c|c|c|c|}
\hline $\begin{array}{l}\text { Phormidium } \\
\text { sp. }\end{array}$ & $0.3187 \pm 0.237$ & $0.8130 \pm 0.467$ & $1.0823 \pm 0.553$ & $0.3693 \pm 0.351$ & $0.0436 \pm 0.039$ & $0.0329 \pm 0.017$ \\
\hline $\begin{array}{l}\text { Arthrospira } \\
\text { sp. }\end{array}$ & $0.0239 \pm 0.015$ & 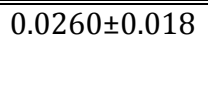 & $0.0361 \pm 0.023$ & 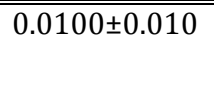 & $0.0007 \pm 0.000$ & $0.0021 \pm 0.002$ \\
\hline
\end{tabular}

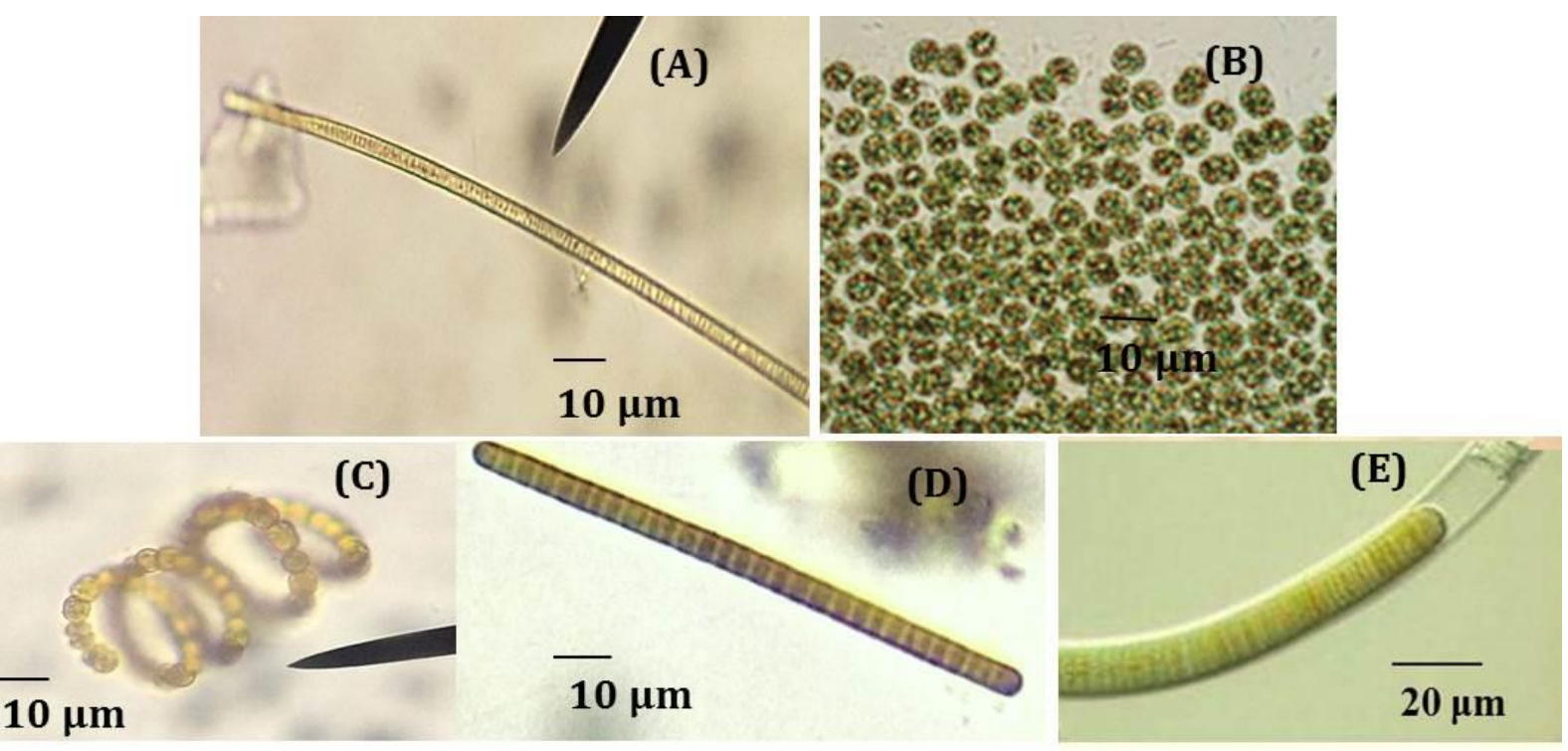

Fig. 2. The dominant cyanobacteria in Phayao Lake: (A) Oscillatoria sp. (B) Microcystis sp.(C) Anabaena sp. (D) Phormidium sp. and (E) Lyngbya sp.

\subsection{Cyanobacteria in Phayao Lake}

Cynobacteria were found to be abundant at the sites adjacent to the city (S1-3) especially in S3. This part of the lake (southeast to eastern portion) is polluted with large cyanobacterial blooms possibly due to nutrient enrichment brought about by the wastewater released from the city and from the livestock effluents. The addition of inorganic nutrients such as phosphorus and nitrogen, to nutrient limited lakes will usually result in increased algal standing crops [13], with cyanobacteria usually dominating. This finding is consistent with the levels of geosmin in water. Species and biomass of cyanobacteria are the factors that affect the MIB and geosmin concentrations in water [14]. It is possible that geosmin-producing Oscillatoria along with Anabaena, [15] contributed significantly to geosmin's prevalence over MIB in the lake.

\subsection{Occurrence of Actinomycetes in Lake Sediments}

The numbers of actinomycetes in the sediment of Phayao Lake varied from 0.80 and $15.47 \times 10^{4} \mathrm{CFU} \mathrm{g}^{-1}$. Most of these belong to the genus Streptomyces with counts ranging from 0.30 to $15.43 \times 10^{4} \mathrm{CFU} \mathrm{g}^{-1}$. Inorganic nutrient enrichment will also stimulate actinomycete growth, but in indirect manner. Actinomycetes are decomposers, and as such, are limited by substrate and nutrient availability. Actinomycetes can decompose resistant organic compounds in the lake, such as cellulose, lignin and chitin from dead lotus plants, which most bacteria cannot. This would seem to further favour increases in actinomycetes populations, since they lack competitors for these energy sources [13]. The abundance of odour-producing actinomycetes in the sediments further indicates that cyanobacteria may not be the only producers of odour in the lake. Inorganic and organic nutrient enrichment of the lake could also directly and indirectly support larger actinomycete populations. This in turn contributed to the associated 
earthy-musty odour detected in the lake. Zaitlin and Watson [16] reported that Streptomyces are the major producers of the geosmin and MIB in terrestrial soil environments. High concentrations of geosmin in lake water were recorded in certain sampling points from several collection periods (S4 in June 2012; S1-6 in September 2012 and; S4-6 in November 2012) particularly at S1-6 (up to $3.74 \mu \mathrm{gL}^{-1}$ ) and MIB at S4 (0.086 $\left.\mu \mathrm{gL}^{-1}\right)$ in September 2012 in the lake despite low abundance of potential odour-producing cyanobacteria during these periods. During periods with a low cyanobacterial biomass, the source of geosmin and MIB has been suggested to be actinomycetes rather than cyanobacteria [17].

\subsection{Odour-Producing Streptomycetes in Sediments}

Thirty-five isolates of Streptomyces spp. were screened (using SPME-GC/MS) for earthy-musty odour production and the morphology of the positive isolates was analysed using scanning electron microscopy (SEM) (Fig. 3). It was found that 30 isolates were odour-producers. Out of the 30 isolates, 22 were exclusive geosmin-producers, 2 produced MIB only and 6 produced both geosmin and MIB (Table 3). The above result was consistent with the results obtained for water and sediment where geosmin was the more prevalent odorous compound than MIB during the period of study. Geosmin was detected in $75.0 \%$ and $54.17 \%$ of the water and sediment samples collected respectively whilst MIB was only detected in $12.5 \%$ of both samples. This finding suggests that the presence of a large number of geosmin-producing Streptomyces spp. could have significantly contributed to the prevalence of geosmin over MIB in both water and sediments of Phayao Lake. Zuo et al. [18] observed Streptomyces was the main species responsible for the earthy-musty odour and produce geosmin more than MIB in Lake Lotus, China.

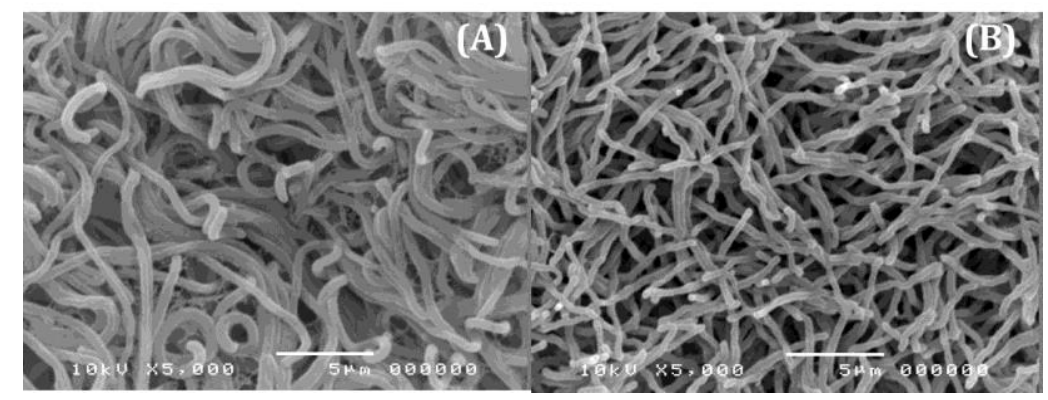

Fig. 3. SEM images of Streptomyces spp. isolated from S-1 (A) and S-5 (B) sediments.

Table 3. Odor Production of Isolated Streptomyces spp. in Sediment $(n=35)$

\begin{tabular}{cc}
\hline $\begin{array}{c}\text { Odor production } \\
\text { characteristics }\end{array}$ & $\begin{array}{c}\text { Number of } \\
\text { Streptomyces spp. }\end{array}$ \\
\hline Odor producer & \\
- Geosmin only & 22 \\
- MIB only & 2 \\
- Both geosmin and & \\
MIB & 6 \\
Non-odor producer & 5 \\
\hline
\end{tabular}

\section{Conclusion}

This study concluded that both filamentous cyanobacteria (Lyngbya sp., Phormidium sp., Anabaena sp. and Oscillatoria sp.) and possibly actinomycetes (Streptomyces spp.) were identified as the earthy-musty odour producers in Phayao Lake. The abundance of Streptomyces emphasizes that cyanobacteria may not 
be the only producers of odours in the lake. The significant concentrations of geosmin and MIB detected in the lake, despite a low abundance of potential odour-producing cyanobacteria in several periods, support the fact that actinomycetes played a role as potential source of these odourous metabolites other than cyanobacteria in Phayao Lake. However, further studies are needed as present data are inadequate to draw conclusions on actinomycetes as a major source of earthy-musty odours in the lake.

\section{Ackowledgement}

The work was carried out with the aid of a grant from the National Research Council of Thailand.

\section{References}

[1] Environmental Research Center. (2005). Middle Development Report to Kwan Phayao. Pitsanulok, Nareasuan University.

[2] Whangchai, N., Wanno, S., Gutierrez, R., Kannika, K., Promna, R., Iwami, N. \& Itayama, T. (2013). Accumulation of microcystins in water and economic fish in Phayao Lake, and fish ponds along the ing river tributary in Chiang Rai, Thailand. Agric. Sci., 4(5B), 52-56.

[3] Juttner, F., \& Watson, S. B. (2007). Biochemical and ecological control of geosmin and 2-methylisoborneol in source waters. Appl. Environ. Microbiol., 73, 4395-4406.

[4] Sugiura, N., \& Nakano, K. (2000). Causative microorganism for musty odor occurrence in eutrophic Lake Kasumigaura. Hydrobiologia, 434, 145-150.

[5] Peerapornpisal, Y. (2013). Freshwater Algae in Thailand. Department of Biology, Chiang Mai University.

[6] Gutierrez, R., Whangchai, N., Sompong, U., Prarom, W., Iwami, N., Itayama, T., Nomura, N. \& Sugiura, N. (2013). Off-flavour in Nile tilapia (Oreochromis niloticus) cultured in an integrated pond-cage culture system. Maejo Int. J. Sci. Technol., 7, 1-13.

[7] Seong, C. N., Choi, J. H. \& Baik, K. S. (2001). J. Microbiol. Soc.-Korea, 39, 17-23.

[8] Chorus, I., \& Bartram, J. (1999). Toxic cyanobacteria in water: A guide to their public health consequences. Monitoring and Management. E \& FN Spon, London.

[9] Watson, S. B. (2003). Cyanobacterial and eukaryotic algal odour compounds: Signals or by-products a review of their biological activity. Phycologia, 42, 332-350.

[10] Zhong, F., Gao, Y., Yua, T., Zhang, Y., Xua, D., Xiao, E., He, F., Zhoua, Q. \& Wua, Z. (2011). Water Res., 45, 6479-6488.

[11] Kaewsri, K., \& Traichaiyaporn, S. (2012). J. Agric. Technol., 8, 537-550.

[12] Prommana, R. (2002). Distribution of toxic algae and water quality in Kwan Phayao, Phayao province in 1999-2000. Master thesis, Chiang Mai University, Chiang Mai, Thailand.

[13] Tierney, D. P. (1976). Actinomycete distribution in northern green bay and the great lakes: Taste and odor relationships in eutrophication of nearshore waters and embayments. Chicago: U.S. Environmental Protection Agency, Region V, Enforcement Division.

[14] Ploeg, M., \& Boyd, C. E. (1991). J. World Aqua. Soc., 22, 207-216.

[15] Smith, P. K., Mahdavi, J., Carvalho, M., Fisher, S., Russell, S., \& Tippett, N. (2008). J. Child Psychology and Psychiatry, 49, 376-385.

[16] Zaitlin, B., \& Watson, S. (2006). Water Res., 40, 1741-1753.

[17] Lanciotti, E., Santini, C., Lupi, E., \& Burrini, D. (2003). Actinomycetes, cyanobacteria and algae causing tastes and odours in water of the River Arno used for the water Supply of Florence. Journal of Water Supply Research and Technology-Aqua, 52, 489-500.

[18] Zuo, Y., Li, L., Wu, Z., \& Song, L. (2009). J. Water Supply: Res. Technol.-AQUA. 58, 552-561. 

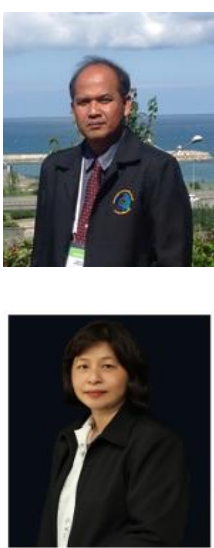

Niwooti Whangchai received his B.S. degree in Prince of Songkla University and his M.S. degree in fisheries science from Kasetsart University, Thailand in 1985 and 1991, respectively. He received his Ph.D. degree in applied biochemistry from University of Tsukuba, Japan in 2002. He is currently a lecturer in the Faculty of Fisheries Technology and Aquatic Resources , Maejo University.

Tipsukon Pimpimon received her B.S. degree in fisheries science from Kasetsart University and M.S. in marine and fisheries science from Aberdeen University United Kingdom in 1985 and 1991, respectively. She is currently a lecturer in the Faculty of Fisheries Technology and Aquatic Resources ,Maejo University.

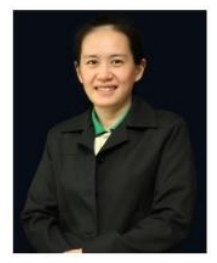

Udomlak Sompong received her B.S. and M.S. degree in biology from Chiang Mai University, in 1998 and 2001, respectively. She likewise received her Ph.D. degree in microbiology from Chiang Mai University. She is currently a lecturer in the Faculty of Fisheries Technology and Aquatic Resources ,Maejo University, Sansai, Thailand.

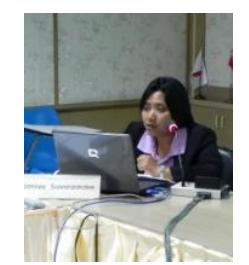

Supannee Suwanpakdee received her B.S. and the M.S. degree in technology of aquatic animal production and agricultural science of fisheries science from Walailak University in 2002 and 2008, respectively. Then she receive her Ph.D. degree in philosophy in fisheries technology and aquatic resources from Maejo University in 2016. She is now a lecturer at the Department of Fisheries, Faculty of Natural Resources, Rajamangala University of Technology Isan, Sakon Nakhon Campus, Sakon Nakhon, Thailand.

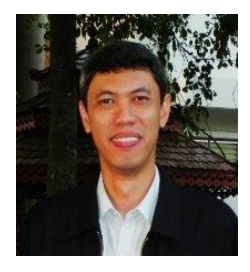

Redel Gutierrez received his B.S. degree in chemistry and M.S. degree in chemistry education from Central Luzon State University. In 2013, he received his Ph.D. degree in fisheries science and aquatic resources from Maejo University. He is currently a lecturer in College of Arts and Sciences, Central Luzon State University, Science City of Munoz, Philippines.

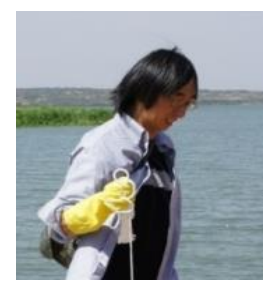

Tomoaki Itayama is currently a professor in Graduate School of Engineering, Nagasaki University, Japan. 